\title{
FENÓMENOS EXISTENCIALES FUNDAMENTALES DE EUGEN FINK: JUEGO Y MUERTE ${ }^{1}$
}

\author{
Cristóbal Holzapfel \\ Universidad de Chile \\ hcristob@yahoo.com
}

\begin{abstract}
Resumen
Eugen Fink propone 5 fenómenos fundamentales de la existencia humana, que son los siguientes: muerte, trabajo, dominio, Eros y juego. En el presente artículo nos ocupamos de dos de ellos: juego y muerte. A modo de destacar algunos de los rasgos primordiales de estos fenómenos -juego y muerte- cabe decir del primero que sobre todo destaca la fantasía, la ficción, y ambos relacionados a su vez con la estructura específicamente lúdica del como-si. De modo espontáneo el niño juega como-si fuera policía, ladrón, rey, plebeyo, padre, madre e incluso niño, es decir, el niño transita con la mayor naturalidad a mundos ficticios. Y esto mismo hará posteriormente el actor profesional. Ello revela a la par el parentesco entre juego y arte. En el caso de la muerte, probablemente lo que más corresponde destacar es su carácter de fenómeno filosófico fundamental, dado que ella se asocia con la concepción del ser en tanto devenir, como que todo lo que es, está transido por el llegar a ser y dejar de ser. Y a la vez que la muerte tiene por lo mismo una peculiar cercanía con el ser, lo tiene también con la nada, y junto con ello, con la pregunta por el sentido.
\end{abstract}

PALABRAS ClAVE: juego, fantasía, ficción, muerte, devenir, transitoriedad.

\section{Abstract}

Eugen Fink proposes 5 fundamental phenomena of human existence, which are the following: death, work, dominion, Eros and play. In this article we are dealing with two of them: play and death. How to highlight some of the key features of these phenomena - play and death-it may be said of the first that stands out above all the fantasy, fiction, and both in turn related to the specifically playful structure of the as-if. Spontaneously the child plays as-if he was police, thief, king, plebeian, father, mother and even child, i.e. the child passes naturally to fictional worlds. And the same will do later on the professional actor. This shows at the same time the relationship between play and art. In the case of death, in the first place should be noted its condition as a fundamental philosophical phenomenon, since it is associated with the conception of being as becoming, which implies that everything that is, is determined by the coming to be and the passing away. Death has therefore a unique proximity to being, as with the nothing, and also with the question about meaning.

KEY WORDS: play, phantasy, fiction, death, becoming, transitority.

El presente artículo es parte del Proyecto Fondecyt 1090224. 
$\mathrm{RB}$ En la expresión 'ser humano', independientemente de su uso habitual, podemos reconocer una relevancia filosófica. Ella acusa una notable cercanía con el pensamiento heideggeriano, por cuanto lo que destaca en ella es que al humano lo compromete un vínculo con el ser, por de pronto, con su propio ser, con el ser de los otros y, en definitiva, de todo, a saber, con el ser de la plenitud. En términos de la Introducción a Ser y tiempo, se trata de que nos va, nos incumbe, nos preocupa el ser de esto o de lo otro, habiendo respecto de ello a su vez la posibilidad de que nos vaya el ser mismo, el ser de la plenitud, como le ocurriría al filósofo.

Más allá de este íntimo vínculo con el ser, que nos define y singulariza, la pregunta es entonces qué somos, quién somos. Para el fenomenólogo Eugen Fink somos ante todo "testigos" (Zeugen), a saber, testigos del ser². Estamos aquí para dar testimonio de nuestra estadía en el mundo. Desde luego, podría decirse de antemano que el ser humano da testimonio a través de sus obras, sean éstas arquitectónicas, artísticas, científicas, políticas, religiosas o filosóficas. Esto no deja de ser cierto, pero implica dar una justificación tal vez demasiado grande e inmerecida a lo que se objetiva, lo que se realiza y se hace. No, más bien se trata de que, por decirlo así, el ser humano es el lugar en el que cada cosa se atestigua -así, el ser de la planta, de la roca, del animal, de la estrella- y, en simetría con ello, el ser humano es el testigo del ser.

¿Debe entenderse esto en el sentido incluso de una suerte de responsabilidad humana de atestiguar, de dar testimonio del ser y de todo lo que es? En principio, no cabría desechar este alcance; es más, él se podría justificar siempre y cuando entendiéramos esa responsabilidad sobre una base óntica, a saber, en el sentido de que el testimonio y el dar testimonio es propio de nuestro ser, de tal manera que la responsabilidad aludida consistiría ante todo en hacerse cargo de esta suerte de mandato del ser. En otras palabras, el ser de la plenitud supone el mandato, en el caso del ser humano, de dar testimonio.

De alguna manera, cabe agregar aquí, significativamente ya el Dasein heideggeriano, como lugar o estancia (Stätte) en que se puede revelar u ocultar el ser, supone todo lo dicho. Pero, no cabe duda, de que el entender esta suerte de lectura del ser en el Dasein (des Seins im Dasein) como testimoniar, le suministra un componente sustancial a la apertura del Dasein, que por eso mismo es el "ahí del ser".

Pero, por otra parte, con Fink podemos decir que el testimoniar no involucra meramente la aludida lectura de los entes y del ser en el ser-humano, sino que, más

2 Fink, Eugen, Grundphänomene des menschlichen Daseins (1995). Edic. Cast.: Fenómenos fundamentales de la existencia humana. Traducción parcial mía con apoyo de Diego Sanhueza, Miguel Pefaur, Edgar Barkemeyer, Carlos Calvo, Gonzalo Parra, Javiera Canales y Lucas Miranda, p. 26. En adelante: 'Ffeh'. <www.observacionesfilosoficas.net/ fenomenosfundamentales.htm> 
bien, somos testigos del ser, porque damos testimonio como amantes, trabajadores, luchadores, jugadores y mortales. Como vemos, respecto del mentado testimonio, el acento está puesto aquí en la acción y, junto con ello, en el vivir, y no simplemente en lo que sería el saber y conocer. Marcando esta peculiaridad de la testimonialidad (Zeugenschaft) finkeana, en todo caso, no queremos decir con ello que el Dasein heideggeriano se limitaría, por su parte, al saber o conocer, dado que la Erschlossenheit (apertura) es co-originariamente a la vez Entschlossenheit (resolución), la que en definitiva conduce a la acción. En razón de ello, lo que marca una clara distinción en el pensamiento de Fink (en contraste con Heidegger) se expresa no solo en términos de entender la apertura como testimonialidad, sino a parejas con ello, entender nuestro dar testimonio a través de lo que él describe como los fenómenos fundamentales de la existencia humana (Grundphänomene des menschlichen Daseins), a saber, Eros, trabajo, dominio (o lucha), juego y muerte. Es decir, en el solo hecho de amar, trabajar, luchar, jugar y morir estamos dando testimonio de nuestro ser-humano, vale decir, del modo como el ser se manifiesta en nosotros y nos determina de peculiar modo. Para el fenomenólogo hay estos cinco fenómenos fundamentales de la existencia humana. Tan solo en el caso del dominio (Herrschaft) hace uso nuestro filósofo de un segundo término afín: lucha (Kampf).

Después de la testimonialidad, podemos considerar como segundo parámetro del análisis fenomenológico de Fink la co-originariedad (Gleichursprünglichkeit), el cual está directamente adoptado de Ser y tiempo. Así como los existenciales: apertura, proyección, yección, resolución, temporalidad, historicidad y, otros están, para Heidegger, en un nivel de igual originariedad, así lo estarían para Fink también los fenómenos existenciales fundamentales: Eros, trabajo, domino, juego y muerte. No hay en esto alguna supuesta prerrogativa ontológica. En este sentido, tanto entrar en Ser y tiempo como en Fenómenos fundamentales de la existencia humana es como entrar en un juego de espejos. Nos podemos mirar en Eros, en el juego, en la muerte o en el trabajo. Ninguno de estos fenómenos es más fundamental, radical u originario que el otro.

Cabe reconocer la enorme relevancia del pensamiento heideggeriano de la cooriginariedad y no solamente en atención a lo que sería de carácter metafísico, sino también antropológico filosófico. Tanto respecto de las concepciones del ser como del ser-humano no vale una instancia, un supuesto principio o determinación como más originaria que otras. Con ello, Heidegger rompe con el prurito de la razón de estar siempre en pos de la búsqueda de un supuesto primer principio, respecto del cual los otros fenómenos serían simplemente derivados.

Un tercer parámetro es el que Fink describe como "Analítica co-existencial”. Si en lo que atañe a los anteriores parámetros se advierte alguna cercanía con Heidegger, en este despunta más bien un distanciamiento. Después de Jaspers, Fink está entre los primeros en detectar lo que podríamos describir con una insuficiente constitución 
ontológica del otro en Heidegger. Después vendrán Lévinas, Adorno y Ricoeur. Esto se advierte sobre todo en lo que concierne a la muerte. A diferencia de Heidegger, en Fink se trata tanto de la muerte propia (Eigentod), como de la muerte ajena (Fremdtod), incluso con la consideración de que, de pronto, y bajo distintas circunstancias, la muerte ajena, del otro, del cercano o familiar, nos va más que la propia. Ello nos muestra una interesante sinergia entre los fenómenos existenciales fundamentales; en este caso sucede que Eros interactúa con la muerte. Es precisamente el lazo amoroso con el otro cercano el que le da plena justificación a la muerte ajena. Pero este Fremdtod guarda relación también con el hecho de que bajo circunstancias extremas y que, al mismo tiempo, se dan a lo largo de toda la historia, la muerte está a disposición de otro, y esto se refiere al matar. Sin este matar no se explica el acontecer histórico. Una somera mirada dirigida a la historia universal nos presenta un campo de guerra y violencia, asociadas al matar. Pero el matar puede ser también el matarse a sí mismo, el sui-cidio, el cual, aparte de Selbstmord, encuentra una expresión muy bella (y romántica): Freitod, la muerte libre. También en este caso sucede que se hace presente la disposición: ahora yo me pongo a mí mismo bajo esa figura, al auto-eliminarme.

Sin duda que el primero en poner claramente de relieve el alcance de la disposición ha sido Heidegger con su pensamiento del Gestell (lo dispuesto) de La pregunta por la técnica y, sobre todo, por el alcance que tiene este Gestell: nada menos el modo cómo se revela el ser en nuestra época y que la determina precisamente por ello como "Era de la Técnica"'s. Desde el río, la montaña, hasta el propio ser humano han ingresado en nuestra era en la esfera del Gestell. Cosas, minerales, animales, plantas, y hasta el propio ser humano está ahí listo para ser explotado, aprovechado y consumido.

Giorgio Agamben atiende a lo que es disponible y lo que no lo es (lo indisponible) de modo esclarecedor en Profanaciones, y ello constituye la base de su concepción de lo sagrado ${ }^{4}$. Justamente lo que caracteriza a esto último -lo sagrado-es una separación, una sustracción, un retiro que hacemos de algo (puede ser cualesquiera objetos: desde la vaca, el astro, la media luna o la cruz), declarándolo con ello indisponible, es decir, que ya no está más bajo la posibilidad del usufructo, de hacer y deshacer con ello, de comprarlo o venderlo, de instrumentalizarlo de cualquier forma. A mi juicio, estamos aquí ante un modo sobresaliente de entender no solo lo sagrado, sino la religión. Agamben encuentra un apoyo respecto de esta concepción en normas del Derecho Romano, en lo cual cita al jurista Trebacio de la época de Julio César.

Además, por cierto, lo planteado por Agamben es crucial al observar cómo nuestra época también está atravesada por la de-sacralización. Igualmente, y con razón, él sostiene que hay en el ser humano esta predisposición a separar algo, y junto con ello, a considerarlo indisponible, de tal modo que la sacralización continúa de Francisco Soler e Introducción a "La pregunta por la técnica" de Jorge Acevedo.

$4 \quad$ Agamben (2005), Profanierungen, Ed. Cast.: Agamben (2005), Profanaciones, p. 83. http://www.revistaminos.com/Agamben,\%20Giorgio\%20-\%20Profanaciones.pdf 
en nuestra época, solo que bajo otros ropajes. Pensemos por ejemplo en lo que atañe a marcas, a figuras mediáticas, a signos y símbolos que se revisten fuertemente de un halo sacro.

La disponibilidad, aunque no haciendo uso de esta misma palabra, se presenta también y de modo decisivo en la fenomenología de Fink. Es más, cabe agregar que ella se relaciona con la impronta más peculiar de esta fenomenología al modo de lo que podríamos describir como "fenomenología dinámica" (el último de los parámetros que destacaremos), vale decir, una fenomenología tal que sale al encuentro del fenómeno (y agreguemos justo para considerarlo en su modo habitual de lo disponible, de lo meramente dado y ajustado a normas, costumbres, creencias, ideologías e ideosincracias).

\begin{abstract}
"Por cierto, generalmente estamos insertos en comunidades fijas, institucionalmente conformadas -antes de reflexionar; vivimos en grupos organizados que en cierto modo, con su maciza doctrina vital, con sus dogmas e ideologías, detienen y aplacan el proceso de autoentendimiento vital, confiriéndole a la socialidad un orden de sentido rígido. Y, pese a ello, irrumpe siempre de nuevo en el hombre con violencia elemental la pregunta, el problema, el estupor y nos expulsa de todos los puertos y seguridades hacia el mar abierto. Por de pronto, nadie inicia la existencia por primera vez, la costumbre tradicional traza ya las vías y andenes de la interpretación vital. Y, sobre todo, la costumbre no tiene solo un carácter informativo; no informa solamente cómo es la vida en todas sus alturas y profundidades, cómo el hombre es cazado por sus instintos y pasiones, cómo lo mueve el anhelo de lo noble y bello. La costumbre exige; tiene muchas figuras para sus exigencias, la suave obligación de las leyes implícitas del decoro y las configuraciones de sentido sancionadas por el derecho humano y divino como propiedad, familia, Estado, etc. La costumbre prescribe cómo se debe vivir. Ella tiene el carácter de una moral pública" (Ffeh., pp. 27-28).
\end{abstract}

Pues bien, a la costumbre, a lo dado, a lo que en la cotidianidad simplemente se asume a-críticamente, se aplica la mencionada "fenomenología dinámica". Sucede que cada fenómeno existencial fundamental ya ha caído bajo determinadas interpretaciones y codificaciones. Ello es inevitable y sin duda que comporta su propia justificación incuestionable. Pero, a la vez, reconocemos una limitación en ello. Pensemos en la muerte que simplemente la vivenciamos de acuerdo a determinado ritual que cambia de cultura en cultura. No sabemos en general cómo morir de otra forma. Eros ya se encuentra también determinado, por ejemplo, por la concepción de lo masuculino y femenino que hay en cada cultura. El trabajo se lo entiende de antemano en función de una concepción política de centro, derecha o izquierda.

Entendida la fenomenología de esta laya, diría que cobra entonces un particular vigor. 
Detengámonos en lo que sigue en la concepción de uno de los fenómenos existenciales fundamentales -el juego. Pero, antes que emprendamos esto, preguntémonos: ¿Por qué los mencionados fenómenos existenciales son fundamentales? Por de pronto, que sean existenciales -Eros-trabajo-dominio-juego-muerte- está claro, ya que todos se refieren a la existencia humana. Es más, Fink opera en esto como Aristóteles, siempre considerando al ser humano como en el espacio intermedio entre el animal y el posible Dios (o también hablando en ello en plural de "los dioses" o "los divinos"). Esto le sirve a Fink para precisar con rigor lo que es estrictamente propio de la existencia humana. Por ejemplo, el dios no necesita trabajar, pero tampoco el animal propiamente trabaja, y aunque se trate de abejas, hormigas o termitas, dado que el trabajar, pero también el amar, luchar, jugar y el morir suponen actos de sentido. En otras palabras, como dadores de sentido que somos (Sinngebende) precisamente damos sentido a lo que hacemos, amando, trabajando, luchando, jugando o incluso muriendo. El caso particular de la muerte en lo que se refiere a su vínculo con el sentido es singular, porque, en verdad, únicamente tiene lugar en este caso el dar sentido en términos de memento mori, de preparación a la muerte. Podríamos agregar que la muerte propiamente tal suscita por de pronto el problema fenomenológico relativo al dudoso estatuto ontológico que pudiera tener la muerte en tanto fenómeno. Justamente lo que caracteriza a la muerte es su sustracción a toda posible fenomenalidad. Sobre ella no tenemos en rigor experiencia alguna posible. Con ella sucede lo de la sentencia epicúrea: cuando ella es, nosotros no somos, y cuando nosotros somos, ella no es. Pues bien, todas estas razones conspiran para darle una justificación a la muerte en tanto fenómeno al modo del memento mori.

Por otra parte, esto se refiere diríamos a la muerte propia (Eigentod). Con la muerte ajena (Fremdtod), este asunto se comporta de distinta laya, en razón de que, si bien igual sucede, como con la muerte propia, que no tengo una experiencia de la muerte del otro (como ciertamente el otro tampoco la tiene respecto de su propia muerte), sin embargo, sí tengo la experiencia, no solo de la preparación a la muerte, sino de la despedida del que ha partido, del recuerdo en la memoria de la familia, de la comunidad, de la nación o incluso de la humanidad toda.

Pero, además, sucede con la muerte que su relación con el sentido es crucial. Es más, entre todos los fenómenos existenciales fundamentales, la muerte es la que primeramente nos deja (incluso inermes) de cara a la pregunta por el sentido. Como bien sabemos, la cuestión es la siguiente: si hemos de morir ¿por qué vivimos?, ¿para qué todo esto? ¿para qué tantos afanes, esfuerzos y sufrimientos?

Y la relevancia de la muerte es aun mayor para la filosofía, desde el momento que está intrínsecamente ligada a la finitud y la transitoriedad. Desde esta perspectiva, podríamos decir que todo muere, que todo lo que llega a ser tiene que dejar de ser, según la necesidad, como reza la sentencia de Anaximandro, el legado escrito más antiguo de la filosofía occidental. No solo plantas y animales, sino montañas, océanos, astros y galaxias, todo está en el pasar y por eso mismo alguna vez ha de pasar. Con Heráclito podemos decir que todo deviene, todo fluye (panta rei). De este modo, la 
muerte nos lanza de golpe a una de las primeras cuestiones que mantuvieran en vilo el filosofar, a saber, si hay simplemente ser, y éste sería permanente, eterno (Parménides) o si solo hay devenir (Heráclito). Mas, con la muerte no hay únicamente este giro, sino que también, desde la perspectiva de Fink, ella es decisiva respecto de la tradición, y junto con ello, de la historia. El pensador de Friburgo destaca cómo vivimos sobre muertos, donde pisemos el suelo terráqueo cubre muertos. En cierto modo, el mundo es de este modo un cementerio. Nuestras ciudades están edificadas sobre muertos. Lo que llamamos "tradición” es únicamente posible sobre esta memoria de cada sociedad y finalmente de la humanidad toda.

Volvamos ahora sobre la pregunta inicial que recién nos planteábamos: ¿por qué los mencionados fenómenos existenciales son fundamentales? La respuesta a esto es asaz sugerente. Es la siguiente: todos los fenómenos cotidianos e históricos que nos determinan a los seres humanos remiten a éstos, a saber, a Eros, trabajo, dominio, juego y muerte. Cuanto hacemos, decidimos, nos preocupa, nos incita, nos acongoja, remite a estos cinco fenómenos existenciales fundamentales. Con ellos se cumple de este modo el cometido de la reducción fenomenológica husserliana: todo fenómeno particular está determinado y remite a los mencionados fenómenos existenciales fundamentales.

Y ahora sí: entremos en el juego. Arranquemos en ello de una brevísima historia de la filosofía del juego. Al respecto, la historia de la filosofía nos revela ciertos saltos gigantescos. Podríamos decir que el tema del juego se abre con Heráclito y su alusión en el Fragmento 52 al niño-rey (basileus), a saber, el cosmos, y que juega. Mas luego hay que esperar hasta el Zaratustra de Nietzsche y su concepción de un hombre (el superhombre) no solo dionisiaco, sino lúdico.

Luego viene una nueva duermevela de la filosofía del juego y hay que esperar hasta 1938, cuando aparece el Homo ludens. El filósofo holandés pone al juego en el origen mismo de la cultura. El hombre, antes que ser homo faber, homo oeconomicus $\mathrm{u}$ otro, es homo ludens. Pero somos tal no simplemente porque juguemos juegos específicos, practiquemos deportes y demás, sino antes que eso, porque nuestro modo de ser ontológico es lúdico. La propia existencia humana tiene de este modo un carácter lúdico. Desde luego, esta dimensión ontológico-existencial del juego está a su vez plenamente asumida por Fink, y justo por ello se entiende que el juego sea uno de los fenómenos existenciales fundamentales.

Casi 20 años después de la revolucionaria obra de Huizinga viene la obra del sociólogo-filósofo Roger Caillois: Los hombres y los juegos ${ }^{5}$. Siguiendo el camino del homo ludens abierto por Huizinga, Caillois nos presenta una reveladora clasificación 
de los juegos: juegos de alea o de azar/destino, agon o de competencia, mimicry o de roles e ilinx o de vértigo. Digamos que en cada caso lo que se trata de entender es que ante todo nos comportamos como homo ludens, por de pronto, un homo ludens agonal. Esta condición agonal se agudiza más encima al generar en definitiva en nuestra época una sociedad de competencia. Y precisamente porque de antemano somos agonales, la gran mayoría de los juegos que jugamos son juegos agonales físicos o mentales.

En cuanto a los juegos de alea, durante milenios éstos fueron vivenciados como juegos de destino. Tengamos en cuenta al atleta griego, para el cual el juego o deporte que practica está ligado a la voluntad divina. Lo que ocurre con la competencia en la que se encuentra es decidido en una instancia no-humana. Ello nos muestra a la vez la relevancia del juego de alea como juego de destino, por cuanto el agon es asumido durante milenios siempre como alea del agon; en otras palabras, no solo tus dotes, talentos, destrezas y habilidades agonales te han sido dadas, sino que lo que hagas con ellas se decide en otra parte. Mas, en la modernidad sucede que el alea comienza a ser manipulado, convirtiéndose estos juegos en juegos de lo meramente alea-torio, de azar.

Desde luego, aunque sucede que sobre todo estos juegos en su dimensión de destino, de lo que en la pre-historia, en la Antigüedad y en el Medioevo tuvo que ver con ordalías, nos hacen sentir que éste es el Gran Juego en el que nos encontramos, con la introducción del azar este carácter de Gran Juego, de un juego en el que estamos puestos desde siempre, no se supera del todo. Por otra parte, únicamente este juego nos lleva a abrirnos a una dimensión extra-humana del juego, esto es, como un juego tal en el que desde siempre nos encontramos y, de alguna manera, tendremos que jugar hasta el final, querámoslo o no, y estés consciente de ello o no. Ya con el solo nacimiento has sido puesto en juego, y luego tendrás que jugar ese juego hasta el final. Todos los juegos, y particularmente los juegos de agon, se debaten dentro de este Gran Juego. Y también sucede esto con los otros juegos: los de mimicry (de roles, simulacro, imitación) y los de ilinx (o de vértigo).

En cuanto a la mimicry, podríamos decir que este juego es el más natural de todos. Debutamos como homo ludens con juegos de mimicry. Ello tiene que ver con nuestra constitución identitaria. Para llegar a ser "yo" comenzamos por ser "otro", y no solamente un "otro humano", sino un "otro-árbol", "otro-río", "otro-montaña" u "otro-caballo", o lo que fuere. El niño juega que es todo eso, y entonces va armando una síntesis analógica del mundo. Aún estamos en una crisálida mítico-poiética. Más tarde, la cruda realidad traerá consigo sus fijaciones, y entonces una nube, el fuego, una roca serán simplemente tales, aquello que nada percibimos por los sentidos.

$\mathrm{Y}$ el ilinx o vértigo, como juego extremo, tiene su fascinosum, en que nos lleva a poner la vida en juego, así las acrobacias, las cuales hoy en día ejercen una atracción irresistible, atendiendo a una cantidad insólita de deportes extremos que se han comenzado a practicar en los últimos decenios. Frecuentemente, y nada más que presas de aquel mysterium fascinosum mortal, tantos jóvenes mueren penosamente en sus prácticas deportivas, desafiando las leyes de la naturaleza. En cierto modo, el juego de ilinx lleva el juego adelante, hacia nuevas y nuevas posibilidades. Y así como el ilinx se expresa en las acrobacias, así en la vida ante todo en los actos heroicos. 
Cabe destacar además que estos actos tienen por lo general un carácter fundacional para una nación. Por otro lado, en particular el ilinx holla una brecha para el agon, ya que después de que se ha tenido éxito en lograr lo que parecía imposible con algún deporte extremo (y probablemente muchos se autoinmolaron por conseguirlo, sin ni siquiera estar conscientes de esa autoinmolación), viene a la zaga el agon, generando una nueva regularidad. Este nuevo juego agonal creado exigirá estrictas mediciones, respeto al reglamento que sea el caso, y que se desarrolle en alguna pista especialmente acondicionada y pulida.

Y así como se advierte aquí interacción con el agon, también el ilinx lo tiene con el Gran Juego, el juego de alea, del azar/destino. Estamos puestos en juego en el juego de alea, que al mismo tiempo consiste en jugar ese juego, que viene a ser al final un juego a la vez del morir.

Corresponde destacar que Heidegger, como filósofo del juego, destaca en 1956, en La proposición del fundamento (Der Satz vom Grund), en especial dos caracteres del jugar que se pueden relacionar justamente con los juegos de alea y de ilinx. Leemos allí lo siguiente:

"Apenas hemos experimentado este juego y no hemos pensado su esencia, a saber, en cuanto a en qué es lo que juega, y quién lo juega, y cómo debe pensarse aquí el jugar. Si aseguramos que el aquí mentado juego, en el que el ser descansa, es elevado e incluso el más elevado juego, libre de todo arbitrio, entonces se dice poco con ello, si acaso esto elevado y lo más elevado no es pensado a partir del secreto del juego".

Y luego:

"La muerte es la donación-de-medida impensada de lo inconmensurable, esto es, del más elevado juego al cual es traído el hombre en la Tierra, en el que él es puesto”.

Un año después de la principal obra de Heidegger sobre el juego -La proposición del fundamento-, en 1957, aparece Oasis de la felicidad (Oase des Glücks), de Eugen Fink, su principal obra sobre el juego ${ }^{7}$ (ya nos haremos cargo del significado de ese título). Pero, antes que eso, aborda en forma no solo compacta sino penetrante el tema del juego en el seminario que dicta sobre los fenómenos fundamentales de la existencia humana, en 1955, en la Universidad de Friburgo en Brisgovia, la obra del mismo nombre que

$6 \quad$ Heidegger (1971), Der Satz vom Grund., p. 186, trad. mía. / Ed. cast.: Heidegger (1991), La proposición del fundamento.

Eugen Fink (1996), Oasis de la felicidad. 
principalmente nos ocupa en el presente artículo y que se publicará en forma póstuma recién en 1979.

Una primera cuestión que le interesa acometer a Fink es lo que atañe a la tensión entre mundo y juego:

\begin{abstract}
“¿Qué es, pues, lo característico de la interpretación cotidiana del juego humano? No otra cosa que el intento de reprimir el juego del núcleo esencial de la existencia, de des-esencializarlo, de concebirlo como un "epifenómeno" de nuestra vida, de quitarle el peso de una genuina significatividad vital. Si bien se observa lo frecuente del juego, el gran interés de los hombres en el juego, la intensidad con que se lo práctica, el aprecio ascendente del juego en conexión con el creciente tiempo libre en una sociedad tecnificada, no obstante se contempla, en general, el juego ante todo como "recreo", como "distensión", como tiempo de esparcimiento y ociosidad alegre, como la "pausa" benefactora, que interrumpe el día laboral o que es la ocupación del día feriado" (Ffeh, p. 223).
\end{abstract}

En definitiva, se trata para nuestro autor del juego como un "entrejuego entre actividades vitales serias" (Zwischenspiel zwischen den ernshaften Lebensaktivitäten). Observamos en esto una cuestión de orden fenomenológico, a saber, que al considerar el juego nada más que como una suerte de epifenómeno, justamente por ello mismo no se lo reconoce propiamente como fenómeno y mucho menos como fenómeno existencial fundamental.

En lo que recién citábamos hay al mismo tiempo otra cuestión crucial que destacar, cual es que el juego desde la mirada de la cotidianidad y de la institucionalidad es considerado como mero tiempo libre, con lo que precisamente se lo rebaja a un mero esparcimiento o recreación respecto de las "actividades serias". Claro está pues que éste viene a ser de este modo un tiempo libre a medias. Esto lo decimos porque uno de los caracteres de mayor relevancia de la concepción finkeana del juego radica precisamente en el tiempo libre. Mas, esta vez se trata de un tiempo libre plenamente independiente, queriendo decir con ello incluso que, entre todos los fenómenos existenciales fundamentales, el juego es el único que nos brinda tiempo libre, y que en contraste con ello, el trabajo y el dominio son los que más suponen un "tiempo ocupado", un "tiempo lleno", es más, una falta de tiempo, un no tener tiempo.

Veamos a continuación cómo en torno a este núcleo del "tiempo libre" podemos visualizar los principales caracteres del juego en Fink. Por de pronto, él se liga a la sin finalidad del juego. Ya en Heidegger, la característica más sobresaliente de su concepción del juego es que éste es sin por qué, razón por la cual se tematiza esto en la obra dedicada a la confrontación del principio de razón suficiente de Leibniz (Der Satz vom Grund, El principio de razón, o también: La proposición del fundamento). En términos heideggerianos, si el ser es fundamento, y todo tiene fundamento o razones siquiera suficientes para ser como es y comportarse como se comporta, el propio fundamento de todo carece, él mismo, de fundamento, y, por lo tanto, es sin por qué, y por eso sería a la 
vez de carácter lúdico. El ser para Heidegger sería no solo lo abierto, el abismo, el don, sino también juego. Ya veíamos que es en el juego del ser en el que estamos puestos en juego. En él tenemos que jugar y jugárnoslas, y hasta en la posibilidad del morir.

En esta sin-finalidad (que, con distintas palabras, desde Heráclito en adelante los principales filósofos del juego han reconocido) radica lo esencial del juego. Con el juego sucede de este modo algo similar a lo que ya Aristóteles reconociera como propio de la filosofía primera (que, a la larga será la metafísica): su condición de saber des-interesado, que justamente por ello se basta a sí mismo. Ahora bien, es tal el poder del mundo de la razón suficiente, en el que a todo se le exige que tenga una justificación y respecto de la cual hay que rendir cuentas, que el propio juego queda también afecto por ello. Y entonces, el juego, se supone, debe tener una justificación pedagógica, y justamente como lo que ya destacaba Fink, como esparcimiento, recreación, como entrejuego (Zwischenspiel) "entre actividades serias". En lo que reconocemos el sinpor-qué y la sin-finalidad lúdica es en el acto mismo de jugar. Junto con Fink, Caillois vio esto con meridiana claridad; para este último se trata de la paidiá, la alegría, el placer de jugar, que puede ascender a algarabía y éxtasis. Y éste es precisamente para Fink el "oasis de la felicidad" del juego, en el que sucede además que perpetuamos el instante, que vivenciamos un eterno presente (así vemos al niño que juega sumido en el juego, sin relación, ajeno al pasado y el futuro).

Nuestro fenomenólogo, que acompañó a Husserl hasta su muerte, advierte a propósito de esto un contrasentido:

"Pero la movilidad lúdica no coincide con las otras formas de movimiento de la vida humana. El hacer restante tiene, en todo lo que se hace, fundamentalmente una referencia interna a la finalidad última del hombre, la felicidad, la eudaimonia. Se toma la vida como tarea, deber, pensum, proyecto - no tenemos una estancia serena; nos sabemos "de camino". Siempre somos expulsados de cada presente, empujados hacia delante por el poder del proyecto vital interno a la finalidad existencial de la eudaimonia. Todos nosotros anhelamos ininterrumpidamente la felicidad, pero de ninguna manera concordamos en lo que ella sea propiamente. Somos puestos en vilo no solo por la inquietud del anhelo de felicidad, sino también por la inseguridad de la interpretación de la "verdadera felicidad". Buscamos granjearnos la felicidad y la realización vital, conquistarla mediante la lucha y el amor, y somos impulsados una y otra vez más allá de todo lo alcanzado, sacrificando cada buen presente por un incierto futuro "mejor". Si bien el juego en tanto jugar es existencia impulsivamente móvil, con todo, está sustraído a todo anhelo inquieto que surge de la impronta de tarea del existir; el juego no tiene finalidades a las que sirva; tiene su finalidad y su sentido en sí mismo. El juego no es por mor de una felicidad futura; ya en sí es "felicidad", está sustraído a todo futurismo general, es un presente que hace feliz, realización sin finalidad. Esto, de ninguna manera, excluye que tenga, en sí mismo, significativos momentos de tensión. Así, por ejemplo, en todos los juegos de competición. Pero el juego no se trasciende. Se mantiene en sí mismo con su excitación, con toda la escala de sus tensiones, con el proyecto de una acción lúdica. Corresponde a las paradojas más profundas de nuestra existencia el que, en la cacería de la felicidad, a lo largo de la vida, no la obtengamos nunca en tanto posesión y que, en un sentido 
pleno, a nadie se le pueda considerar feliz antes de su muerte - $\mathrm{y}$, sin embargo, cuando interrumpimos temporalmente aquel anhelo, inadvertidamente llegamos a un "oasis" de felicidad" (Ffeh, p. 225).

Por otra parte, al juego le es propio una fantasía, una ficcionalidad específica. Ello muestra la cercanía que hay entre arte y juego. El cuadro colgado en la pared de Jacques-Louis David, que representa a Sócrates en el lecho de muerte rodeado de sus amigos, es como una ventana que nos transpone a otro tiempo y espacio. En ello se hace presente no solo la metáfora, la analogía, la verosimilitud, sino también lo que sería un "como-si" específicamente artístico. Mas, este como-si, como todos estos otros conceptos afines son también propios del juego (en lo cual nuevamente coinciden los filósofos del juego). También se adivina en ello nuevamente un componente metafísico del juego, por cuanto da lugar a una concepción de la posibilidad. El juego nos permite entrar en un mundo de posibilidades y, en contraste con ello, la realidad se presenta como el resultado de posibilidades justamente realizadas, las cuales ya quedan prendadas en ciertas fijaciones: esto es esto, $\mathrm{y}$ tiene tales propiedades.

Y es verdaderamente extraordinario (cuando no algo de carácter sublime) que todas estas determinaciones que hemos destacado se den simplemente como un regalo, con toda la exquisita candidez que a ello le acompaña, en la infancia:

“La niña pequeña que juega vive al mismo tiempo en dos ámbitos, en la realidad ordinaria, y en una esfera irreal, imaginaria. En sus juegos designa la niña la cosamuñeca como un niño -el juguete tiene un carácter mágico, en sentido estricto no surge en la fabricación industrial, tampoco surge a partir de un proceso laboral, surge en el jugar y a partir del jugar en tanto éste es un proyecto de una peculiar dimensión de sentido que no se ajusta a lo real, sino que flota como una apariencia inaprensible sobre ello. Se abre un campo de lo posible que no está atado al curso de los sucesos reales, un escenario que si bien requiere y emplea sitio, ocupa tiempo y espacio, no es, sin embargo, un trozo del espacio y tiempo reales mismos -un sitio irreal en un espacio y un tiempo irreales. El juguete tiene su lugar cuando no lo vemos desde fuera como una manufactura, sino desde la mirada del jugador en el contexto de sentido abarcador del mundo lúdico" (Ffeh, p. 228).

Lo que recién leímos significa que en verdad el niño habita en un mundo imaginario, en un espacio y tiempo irreales y está rodeado de cosas que convierte en juguetes, los cuales también están ontológicamente determinados por la dimensión del comosi. Y ello abarca incluso el mundo entero: no solo el oso peluche es como-si fuera oso, sino la nube es como-si fuera dragón y la estrella es como-si fuera la abuela que ya partió.

A la ficción y al como-si se agrega todavía el revelador carácter de la iteración (que también comparten el juego y el arte). Tal como lo podemos apreciar en El jugador, de Dostoievsky, el juego da lugar a la posibilidad del juego en el juego, y esto con un doble alcance (como en Hamlet): juego en el juego propiamente tal y, lo que es más interesante, como en Dostoievsky, juego en que al mismo tiempo se está siendo parte del "juego de la vida": Los jugadores de Rulletenburg están a la vez a la espera de que la 
Mamushka, la tía rica de San Petersburgo, muera, y así heredar uno de ellos (su sobrino, el Coronel) pudiendo de este modo seguir jugando ${ }^{8}$. Mas, nuevamente destaquemos que todo ello junto con darse patentemente en el arte (y no solo en Las Meninas, en que el pintor está dentro del cuadro, sino en el drama, en el cine y, en rigor, en toda forma de arte) se da también y de modo completamente espontáneo en el juego:

"La posibilidad de iteración del juego tiene algún parentesco con la estructura de iteración de la pictoricidad. El juego se puede repetir en el juego. Dicho muy simplemente: niños que juegan el antiquísimo juego de imitación, que en su mundo lúdico son "padre" y "madre" y tienen "niños", pueden enviar a estos niños del mundo lúdico nuevamente fuera de casa al "juego" en la calle, hasta que el bizcocho de arena esté horneado. Pero ya en este ejemplo se puede reconocer algo significativo. El juego no sabe meramente de la iteración de tipos iguales, precisamente de que se presentan juegos en juegos -el juego abarca en su zona imaginaria de la representación justamente el comportamiento humano no lúdico. El juego humano como uno de los cinco fenómenos fundamentales se comprende a sí mismo, como también a los otros cuatro" (Ffeh, p. 250).

Da qué pensar no solo la ficción, sino la iteración lúdica, por cuanto -a mi juicio-radica en ello una de las explicaciones del embrujo del juego, precisamente porque en su seno, y de un modo analógico, se patentiza la vida y sus conflictos, sus altibajos, sus avatares, su triunfo y derrota. En efecto, el juego puede generar visiblemente ludopatía. Es el caso no solo del propio Dostoievsky, como jugador de ruleta, sino del protagonista del El jugador-Alexei-y justamente en él, de modo ejemplar, se torna manifiesta la conexión que ahora destacamos: entre juego e iteración. Alexei pretende a la hija del Coronel, pero ella no se interesa por él, simplemente porque es un humilde secretario. Esto induce a Alexei a jugar un juego que él mismo califica como "plebeyo", porque juega con-por-qué, con la finalidad de hacerse rico a través del juego, intentando con ello hacer que ella se interese por él. Advirtamos al respecto como Dostoievsky está perfectamente consciente del genuino sin-por-qué del juego y que Alexei mira con resentimiento en los caballeros que en Rulettenburg juegan nada más por jugar. Y el resultado final de esto es dramático: el pobre Alexei acaba destruido, al final de la obra semeja un harapo humano.

\section{en Hamlet:}

La doble posibilidad de la iteración, como adelantábamos, se expresa ejemplarmente

"Cuando el príncipe danés, vacilante por mucho tiempo, hace estrenar en el mundo lúdico una obra teatral que representa el asesinato del rey, y a través de esta representación desenmascaradora conduce a la madre criminal y a su cuñado a un callejón sin salida, entonces la comunidad lúdica también ve, pues, la segunda comunidad lúdica en juego, es testigo de su hechizo aterrador -y es ella misma embrujada y hechizada" (Ffeh, p. 240). 


\section{Referencias bibliográficas y abreviaturas}

FFEH: Fink, Eugen, Grundphänomene des menschlichen Daseins (1995). Friburgo en Brisgovia: Karl Alber / Edic. Cast.: Fenómenos fundamentales de la existencia humana. Traducción parcial mía, con apoyo de Diego Sanhueza, Miguel Pefaur, Edgar Barkemeyer, Carlos Calvo, Gonzalo Parra, Javiera Canales y Lucas Miranda. <www.observacionesfilosoficas.net/fenomenosfundamentales.htm>

Agamben (2005), Profanierungen, Frankfurt am Main: Suhrkamp. / Ed. Cast.: Agamben (2005), Profanaciones. Trad. de Flavia Costa y Adriana y Edgardo Castro. Buenos Aires: Adriana Hidalgo Editora. http://www.revistaminos.com/ Agamben,\%20Giorgio\%20-\%20Profanaciones.pdf

Caillois (1967), Los juegos y los hombres. Trad. de Jorge Ferreiro. México: FCE.

Dostoievsky (1991), "El jugador”, Obras Completas. Trad. de Rafael Cansinos Asséns. Madrid: Aguilar.

Fink, Eugen (1996), Oasis de la felicidad. México: UNAM.

Heidegger (1993), "La pregunta por la técnica", en Heidegger, Ciencia y técnica. Prólogo de Francisco Soler e Introducción a "La pregunta por la técnica" de Jorge Acevedo. Santiago: Universitaria.

(1971), Der Satz vom Grund. Pfullingen: Neske, trad. mía. / Ed. cast.: Heidegger (1991), La proposición del fundamento. Trad. de Félix Duque y Jorge Pérez de Tudela. Barcelona: Serbal-Guitard. 